\title{
The evolution of humanitarian logistics as a discipline through a crystal ball
}

The evolution of humanitarian logistics

\author{
Driehaus College of Business, DePaul University, Chicago, Illinois, USA \\ Gyöngyi Kovács \\ HUMLOG Institute/Supply Chain Management and Social Responsibility, \\ Hanken School of Economics, Helsinki, Finland, and \\ Karen Spens \\ Supply Chain Management and Social Responsibility/Dean's Office, \\ Hanken School of Economics, Helsinki, Finland
}

Nezih Altay

\begin{abstract}
Purpose - Humanitarian logistics has for a long time been argued to be a new discipline. Now that even the Journal of Humanitarian Logistics and Supply Chain Management (JHLSCM) has existed over a decade, it is time to take a closer look at its evolution. This article provides some understanding for the developments of humanitarian logistics over the past decade, reveals current trends and discovers what lies behind the curtains in the humanitarian logistics and supply chain management discipline.

Design/methodology/approach - This article brings in developments and discussions in humanitarian logistics practice into the research domain.

Findings - The article conveys the concerns of humanitarian logistics practitioners to research. These include the backlash from the COVID-19 pandemic as a prime current concern, and also other longer-term issues and developments.

Research limitations/implications - The themes identified in the article can be used to inform a research agenda in humanitarian logistics and supply chain management. The article revisits a framework of global events and their cascading impacts to include non-linearities and multiple disruptions from evolutionary disasters such as the COVID-19 pandemic.

Practical implications - The article argues for more collaborative and co-designed research to increase the relevance and impact of humanitarian logistics.

Social implications - Wider societal views are brought into the area of humanitarian logistics.

Originality/value - The article highlights the gaps that remain in humanitarian logistics and supply chain management research.
\end{abstract}

Keywords Humanitarian logistics, Inter-organisational co-ordination, Humanitarian supply chain, Supply chain disruption, Pandemic response, Cash-based intervention

Paper type Research paper

\section{Introduction}

Humanitarian logistics has for a long time been argued to be a new discipline. While research in this discipline was indeed very scant prior to the mid-2000s, it has seen explosive growth

(C) Nezih Altay, Gyöngyi Kovács and Karen Spens. Published by Emerald Publishing Limited. This article is published under the Creative Commons Attribution (CC BY 4.0) licence. Anyone may reproduce, distribute, translate and create derivative works of this article (for both commercial and noncommercial purposes), subject to full attribution to the original publication and authors. The full terms of this licence may be seen at http://creativecommons.org/licences/by/4.0/legalcode

This research could not have been achieved without the kind support of the H2020-SC1-PHECORONAVIRUS-2020 Project No. 101003606 HERoS (Health Emergency Response in Interconnected Systems).

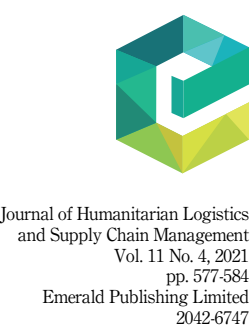


JHLSCM 11,4

since a few seminal articles had come almost simultaneously yet oblivious of one another in 2005-2007: Altay and Green (2006), Kovács and Spens (2007), Oloruntoba and Gray (2006), Pettit and Beresford (2005) and Van Wassenhove (2006). This growth is well documented in countless systematic literature reviews that were already summarised in a meta-analysis by Kunz and Reiner (2012). Since then, reviews including meta-analyses have taken more focused approaches and narrowed down their scope to specific topics and perspectives.

Avoiding duplications, this article takes a different approach to reviewing the developments of humanitarian logistics over the past decade by bringing in the insights from the latest Global Logistics Cluster (GLC) meetings and the Humanitarian Networks and Partnerships Week (HNPW) 2021. The article further revisits Kovács' (2018) last outlook from Tatham and Christopher's (2018) third edition of their anthology on humanitarian logistics and a fourth edition of which is currently in the making. Both that and the very fact that even the Journal of Humanitarian Logistics and Supply Chain Management (JHLSCM) has existed over a decade, illustrate that the discipline has undergone a massive evolution. This article provides some understanding for the developments of humanitarian logistics over the past decade, reveals current trends and discovers what lies behind the curtains in the humanitarian logistics and supply chain management discipline.

What lies behind the curtain is partly rooted in the discipline itself due to systemic changes within the discipline, such as the move towards cash-based interventions, while others originate from outside of the discipline, as is the large-scale impact of the COVID-19 pandemic not only on just pandemic response but also on how aid is delivered overall. Humanitarian logistics thus needs to constantly reinvent itself. Hence, we look behind the curtains to reveal major issues and project them through our crystal ball. In this regard, this article steps out of the typical literature review to shed light on further developments spotted in humanitarian logistics practice.

\section{Discovering the state of the art of humanitarian logistics}

This being the tenth anniversary issue of JHLSCM, it is time to cherish the fact that humanitarian logistics as a discipline has developed and matured. Ten years ago, it was mainly various special issues in other journals that carried the torch. Not only has that been consolidated into this publication outlet, but also JHLSCM has managed to maintain its unique focus, its role in advancing the discipline, as well as its strong link to humanitarian logistics practice. The latter is the more important as the discipline still suffers from much talk and little application (Besiou and Van Wassenhove, 2020) and many highly sophisticated models without a reality and feasibility check. Luckily for JHLSCM, there are practitioners involved in some of that feasibility check, while academics continue to focus on assuring the scientific quality and methodological rigour of the articles. Thereby the journal contributes to filling the biggest gap in the discipline: research with rigour and relevance.

As prior systematic literature reviews and meta-analyses indicate, there is an overall explosion of articles in humanitarian logistics, and also, a turn towards methodological rigour in the quantitative space (Kovács and Moshtari, 2019). Other methods are not as solidified, perhaps, which is what JHLSCM wanted to address by its methods special issue in 2019. Field research is surprisingly little exercised, though there is good advice to be had in Sohn's (2018) chapter on the matter. Case research has matured somewhat more (Vega, 2018), though few in situ observations or hands-on experiences of those who work both in research and practice, and/or of collaborative endeavours of researchers and practitioners have turned into publications. The latter has though started to catch on as a result of more co-defined research problems and truly collaborative research. This is a prime way of ensuring not only rigour and relevance but also the potential impact of the research. Yet the discipline is far from using 
the entire vast spectrum of potential research methods and has also tapped in surprisingly little to the potential that many technology-driven data collection methods would offer.

The interest in humanitarian logistics has not dwindled in other journals, either. This interest is often (re-)fuelled by specific large disasters, or catastrophes, as Holguín Veras et al. (2012) would classify them. Lately, it has been the COVID-19 pandemic that has drawn more attention to humanitarian logistics, including to what we can learn from humanitarian organisations in responding to larger supply chain disruptions (Kovács and Falagara Sigala, 2021). By and large, however, the discipline has still ignored the area of conflicts, wars and complex emergencies, even though they had until recently accounted for the vast majority of humanitarian deliveries. The year 2020 saw a turn in that, however, with now even the majority displacements being weather-related (Climate Centre, 2021).

The pandemic blurs the already much discussed distinction between "natural" disasters (if there are any such, Kelman, 2020) and man-made ones. Yet organisational mandates still follow both thematic areas as well as the distinction between conflicts and complex emergencies vs. the absence of these in a disaster. Mandates can also be confined to specific geographical areas: as the "refugee crisis" around 2015 illustrated in the EU and also the pandemic highlights around the world. Importantly, organisational mandates and their restrictions also impact on resource configurations and their activation (Kovács and Tatham, 2009), and thereby, on the humanitarian supply chain.

Interestingly, Kovács (2018) already included pandemics as a "threat scenario" when illustrating the potential impacts of global events in other locations. That framework was a result of understanding the combined effects of various events and their cascades around the world. Central to the framework were supply chain disruptions; although it included pandemics as a potential cascade of various events, it did not see them as a source of (further) disruptions. This is now updated in Figure 1.

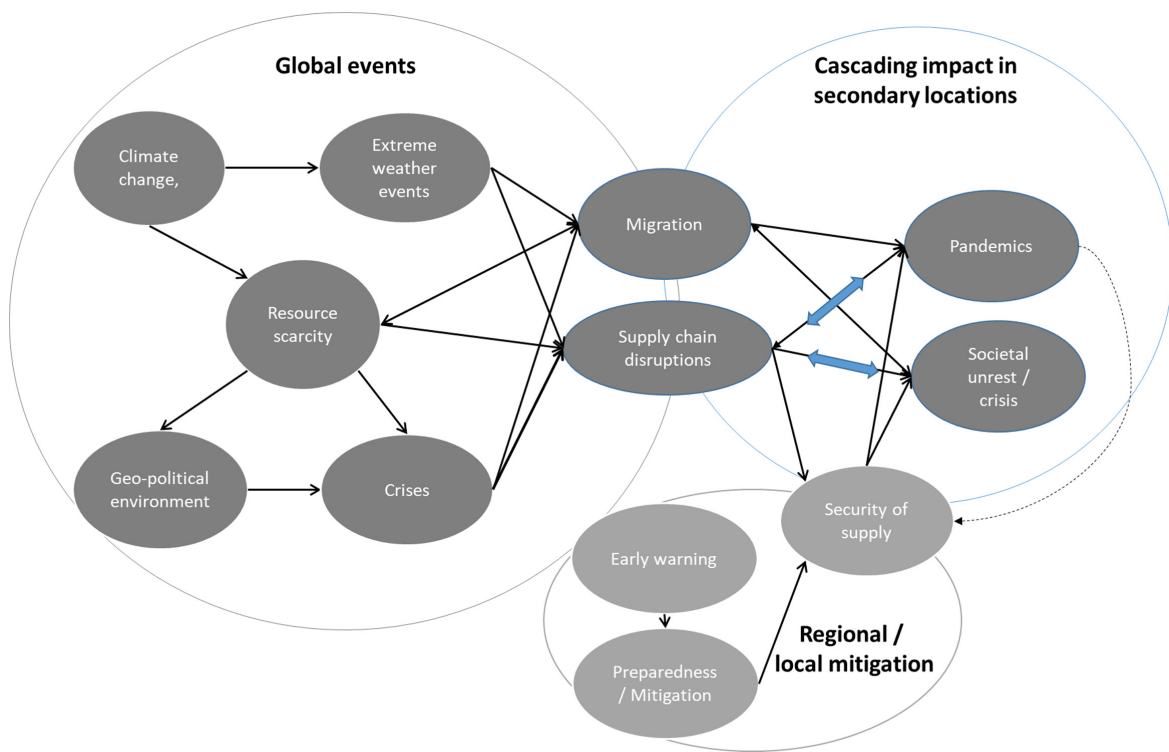

Note(s): Modified from Kovács, 2018, p. 326
The evolution of

humanitarian logistics

579
Figure 1.

Global events and their cascading impacts around the world 
JHLSCM 11,4

This new framework continues to emphasise a security of supply approach. Often used for energy supply, or in the military, the concept of security of supply ensures the functioning of society through a crisis, directly aimed at mitigating supply chain disruptions (Kachaliet al., 2018). As Vanhanen (2020, p. 147) puts it, "security of supply refers to the ability to maintain the basic economic, critical infrastructure and other societal functions that allow the continuation of normal life in the event of major disruption". It needs to be noted, however, that security of supply is an inherently localised approach, whereby the country in question prepares for the eventualities of disruptions. This is at the heart of localisation, local capacity building and even the endeavours of finding local suppliers also for humanitarian deliveries.

Importantly, the framework also recognises the interrelations between the cascading impacts and further supply chain disruptions, as well as the impacts of pandemics back on security of supply. What is more is that, pandemics as well as climate change-induced migration and geopolitical events are constantly evolving. There is an interesting dualism between their impact and the recovery from them, resulting in non-linearities and multiple points of disruptions. Thus, rather than being unidirectional impacts through cascades, there are some feedback loops to be considered - although the jury is still out on whether this is a different type of "evolutionary" disaster altogether.

\section{Behind the curtains: global new and old concerns}

To date, much of humanitarian logistics research has been recentred on pandemic response, and not surprisingly, supply chain disruptions. This is also visible in some of the most recent special issues of JHLSCM and its upcoming vaccine supply chain special issue. Pandemic research is not new to humanitarian logistics, although it was still regarded as way too scant in 2018 (Mbohwa et al., 2018). JHLSCM could, however, quickly put together an early virtual special issue on learnings from past pandemics and epidemics at the onset of the COVID-19 pandemic.

What is new, is the global interest across all journals in this type of research - and of course the devastating global impact of the COVID-19 pandemic. One could even turn Figure 1 around and start with the pandemic all the way to its impact on resource scarcity, hunger and migration; as it is due to the pandemic, many other humanitarian programmes were halted or their funding much reduced. Although not a cyclical or reoccurring disaster per se, a pandemic such as this one defies the typical preparedness-response-reconstruction approach. It is not a cascading disaster; albeit there are observable incident evolutions, various decisions as well as variants of concern restart the response, while the pathways from the pandemic to other disasters are unattended to create new incident evolutions. This has been much discussed at the latest GLC meeting (Apr 2021) as well as at the Humanitarian Networks and Partnerships Week (HNPW) overall that the authors participated in. In the GLC meeting, the "backlash from COVID-19" was cited as the number one concern across humanitarian organisations. Beyond the humanitarian programmes that did not receive funding and the disasters that were not properly attended to due to COVID-19, this backlash also extends to the changing incident evolutions of these disasters, and thereby to different, even larger requirements on disaster response operations.

The COVID-19 pandemic is of course not the only current concern among humanitarian logistics practitioners. Many other concerns revisit trends and developments that have been in place for a much longer time already. Table 1 combines insights about previous trends and concerns as identified in Kovács (2018) and at the GLC/HNPW meetings and their updates.

Some of these developments merit some special mentions. As the framework highlights (see Figure 1), numerous factors, not the least climate change, trigger migration. By 2020, weather and climate accounted for most displacement (Climate Centre, 2021). Thus, 
\#

1.1 Shift from inter-agency co-ordination to relationship management

1.2 Emphasis of the sustainability of aid

1.3 Servitisation of humanitarian logistics

1.4 Standardisation and modularisation

1.5 New technologies changing the response

2.1 Shift towards cash transfer programmes/ cash-based initiatives (CBI)

2.2 Focus on supply chain visibility

2.3 Extension of professionalisation to implementing partners

2.4 Interoperability across humanitarian organisations

2.5 Heightened security focus

3.1 Product and process innovation

3.2 Scalability

3.3 Back to basics - the need to deliver prevails

3.4 Catering to people on the move

3.5 New systemic changes

NEW Backlash from COVID-19 ${ }^{\mathrm{b}}$
Recent developments and outlooks

Renewed importance of co-ordination in conflict zones ${ }^{\mathrm{a}}$ Ecosystems of co-ordination, i.e. groups instead of individual organisations negotiating with one another ${ }^{b}$ Focus on capacity building and localisation, ${ }^{\mathrm{a}, \mathrm{b}}$ Importance of surge capacity ${ }^{\mathrm{a}}$

More emphasis on greening, waste management and reverse logistics ${ }^{\mathrm{b}}$

Link between sustainability and resilience ${ }^{\mathrm{b}}$

Procurement of services to one another

Service tiering in the last mile ${ }^{\mathrm{a}}$

Access concerns ${ }^{\mathrm{a}, \mathrm{b}}$

Kitting in health programmes ${ }^{\mathrm{a}}$

Updates of SPHERE standards ${ }^{\mathrm{a}}$

Renewed focus on inter-agency health kits in the pandemic

Universal logistics standards project

More reliance on data from social media ${ }^{a}$

Importance of link to interoperability ${ }^{\mathrm{a}, \mathrm{b}}$

Digitalisation and the continued problem of the digital divide $^{b}$

Second wave of servitisation ${ }^{\text {a }}$

Recognition of the limits of CBIs if markets or technologies fail or in catastrophic events ${ }^{b}$

Shift in focus towards the duality of pre-positioning and CBIs $^{b}$

Tracking and tracing endeavours ${ }^{\mathrm{a}}$, the transparency conundrum between outsourcing to LSPs, own delivery vs innovation ${ }^{\mathrm{a}}$

Renewed interest in common data models and ERP systems $^{b}$

Continued focus on localisation ${ }^{\mathrm{b}}$

Interconnectivity and interoperability in light of consolidation $^{\mathrm{b}}$

Access concerns in conflict zones ${ }^{\mathrm{b}}$

Public procurement for innovation ${ }^{\mathrm{a}}$

Beyond technology ${ }^{\mathrm{a}}$

Digitalisation $^{\mathrm{b}}$

Preparing host supply chains to be able to absorb surge capacity $^{\mathrm{a}}$

Recognition of the limits of localisation in catastrophic events

Backing up $\mathrm{CBIs}^{\mathrm{b}}$

Mobile approaches needed for refugee and migrant population $^{\mathrm{a}}$

Preparedness for climate refugees

Co-creation, sharing economy impacting on

humanitarian deliveries

Disruptions to the humanitarian supply chain
The evolution

humanitarian

logistics

581

Note(s): The numbering of trends follows the editions of the Tatham and Christopher's book series. ${ }^{a}$ Kovács (2018), ${ }^{b}$ GLC/HNPW meetings (2021)

Table 1.

Old and new concerns in humanitarian logistics 
JHLSCM 11,4

preparedness for more displacement will be key, and logistically, this will mean preparedness for serving people on the move, or people who are absorbed among urban population. Refugee camps, though mighty, are not the only locations where such people of concern are located.

In parallel, it has been long recognised that localisation and local capacity building are key to community resilience, and ultimately, to lowering the overall needs for any external humanitarian aid. Humanitarian organisations have also tried to include more and more local suppliers in their activities, though they are often facing challenges in terms of quality, capacity, lead times and delivery terms. This is at times a challenging endeavour in light of procurement requirements of years of proven existence and financial reports, especially for small and medium sized companies everywhere. Yet, it is also a very important and rewarding enterprise to support such companies and their capacities for being integrated in humanitarian endeavours. At the end of the day, this will also increase the possibility of host nations to absorb any surge capacity that is needed, when a disaster outstrips their own capacities. A focus on scalability, and absorptive capacities, was further highlighted by the COVID-19 pandemic, where hospitals at the stretch of their intensive care unit capacities lacked the ability to onboard further medical staff that would have been necessary to be able to serve unusually large numbers of patients (Uimonen et al., 2020).

Localisation further includes the facet of meeting the diversified needs of beneficiaries. In the commercial sector, this is a question of customisation to specific needs. In the humanitarian sector, it will require not only considering stratified vulnerable population as is already the case with the elderly, women and children, and increasingly, through disability inclusion and a wider view on gender inclusion programmes, but the same view in mitigation, preparedness and response. The question is how this will impact on logistics and supply chain management.

\section{Conclusions}

Humanitarian logistics is a maturing discipline, and we would like to extend our deepest gratitude to the entire community contributing to it, and to JHLSCM, in such a solidary, ever constructive manner. The authors of the seminal papers in the mid-2000s may not have known of one another's work then, but have since continued to inspire one another, comment on each other's work, and improve the discipline's quality, rigour and relevance.

Our work is not done; however, old issues may be resolved but new challenges appear all the time. The backlash from COVID-19 and the disruptions it has caused in humanitarian supply chains are but one important concern to tackle. Many more have been listed in Table 1. Importantly, the table, and this article, extends other review articles by bringing in the voices of practitioners and reporting on the concerns discussed amongst them. Humanitarian logistics researchers need to continue listening to practitioners to ensure the relevance of their research. In this we would like to extend beyond Besiou and van Wassenhove's (2020) call to do so and encourage researchers and practitioners to collaborate, co-design projects, and coauthor articles. JHLSCM is a great platform for those.

That being said, we have much to learn from other disciplines. There is surprisingly little cross-fertilisation of research topics or approaches even with disaster risk reduction, and disaster management, not to speak of public health, or international humanitarian law and refugee law. Much more could be done to push the boundaries of the discipline.

Last but not least, humanitarian logistics should become a discipline and a concept that is more broadly understood and known in society and to have an even broader impact. This is, as we see it, one of the major issues that we would want to reveal behind the curtains and the future to be foretold in our crystal ball. 


\section{References}

Altay, N. and Green, W.G. III (2006), "OR/MS research in disaster operations management”, European Journal of Operational Research, Vol. 175 No. 1, pp. 475-493.

Besiou, M. and Van Wassenhove, L.N. (2020), "Humanitarian operations: a world of opportunity for relevant and impactful research", Manufacturing and Service Operations Management, Vol. 22 No. 1, pp. 135-145.

Climate Centre (2021), Three Out of Four Displacements in 2020 Were Weather-Related, Climate Centre, The Hague, available at: https://www.climatecentre.org/4978/three-out-of-four-newdisplacements-in-2020-were-weather-related/(accessed 23 June 2021).

Holguín-Veras, J., Jaller, M., Van Wassenhove, L.N., Pérez, N. and Wachtendorf, T. (2012), "On the unique features of post-disaster humanitarian logistics", Journal of Operations Management, Vol. 30 Nos 7-8, pp. 494-506.

Kachali, H., Storsjö, I., Haavisto, I. and Kovács, G. (2018), "Inter-sectoral preparedness and mitigation for networked risks and cascading effects", International Journal of Disaster Risk Reduction, Vol. 30, pp. 281-291.

Kelman, I. (2020), Disaster by Choice: How Our Actions Turn Natural Hazards into Catastrophes, Oxford University Press, Oxford.

Kovács, G. (2018), "Where next? A glimpse of the future of humanitarian logistics", in Tatham, P. and Christopher, M. (Eds), Humanitarian Logistics: Meeting the Challenge of Preparing for and Responding to Disasters, 3rd ed., Kogan Page, London, pp. 316-330.

Kovács, G. and Spens, K.M. (2007), "Humanitarian logistics in disaster relief operations", International Journal of Physical Distribution and Logistics Management, Vol. 37 No. 2, pp. 99-114.

Kovács, G. and Moshtari, M. (2019), "A roadmap for higher research quality in humanitarian operations: a methodological perspective”, European Journal of Operational Research, Vol. 276 No. 2, pp. 395-408.

Kovács, G. and Tatham, P. (2009), "Responding to disruptions in the supply network - from dormant to action", Journal of Business Logistics, Vol. 30 No. 2, pp. 215-229.

Kunz, N. and Reiner, G. (2012), "A meta-analysis of humanitarian logistics research", Journal of Humanitarian Logistics and Supply Chain Management, Vol. 2 No. 2, pp. 116-147.

Kovács, G. and Falagara Sigala, I. (2021), "Lessons learned from humanitarian logistics to manage supply chain disruptions", Journal of Supply Chain Management, Vol. 57 No. 1, pp. 41-49.

Mbohwa, C., Chingono, T. and Buatsi, P. (2018), "Humanitarian logistics and supply chain management in Africa”, in Tatham, P. and Christopher, M. (Eds), Humanitarian Logistics: Meeting the Challenge of Preparing for and Responding to Disasters, $3^{\text {rd }}$ ed., Kogan Page, London, pp. 142-167.

Oloruntoba, R. and Gray, R. (2006), "Humanitarian aid: an agile supply chain?", Supply Chain Management: An International Journal, Vol. 11 No. 2, pp. 115-120.

Pettit, S.J. and Beresford, A.K. (2005), "Emergency relief logistics: an evaluation of military, nonmilitary and composite response models", International Journal of Logistics: Research and Applications, Vol. 8 No. 4, pp. 313-331.

Sohn, M. (2018), "Ch.5 So much of research is context: fieldwork experience in humanitarian logistics", in Kovács, G., Spens, K.M. and Moshtari, M. (eds.), The Palgrave Handbook of Humanitarian Logistics and Supply Chain Management, Springer Nature, London, pp. 149-177.

Tatham, P. and Christopher, M. (2018), Humanitarian Logistics: Meeting the Challenge of Preparing for and Responding to Disasters, 3rd ed., Kogan Page, London, pp. 316-330.

Uimonen, T., Mulari, M., Niemi, A., Rissanen, A., Nuutinen, M., Riipi, T., Väljä, A., Karvinen, S., Haavisto, I., Leskelä, R.-L., Boersma, K. and de Vries, M. (2020), "D2.2 Healthcare system
The evolution

of

humanitarian

logistics

583 
JHLSCM 11,4

584 analysis”, Health Emergency Response in Interconnected Systems, p. 91, available at: https:// www.heros-project.eu/output/deliverables/(accessed 4 Feb 2021).

Van Wassenhove, L.N. (2006), "Humanitarian aid logistics: supply chain management in high gear", Journal of the Operational Research Society, Vol. 57 No. 5, pp. 475-489.

Vanhanen, H. (2020), "COVID-19 and European security of supply: growing in importance”, European View, Vol. 19 No. 2, pp. 146-153.

Vega, D. (2018), "Case studies in humanitarian logistics research", Journal of Humanitarian Logistics and Supply Chain Management, Vol. 8 No. 2, pp. 134-152.

\section{Corresponding author}

Gyöngyi Kovács can be contacted at: gyongyi.kovacs@hanken.fi

For instructions on how to order reprints of this article, please visit our website: www.emeraldgrouppublishing.com/licensing/reprints.htm Or contact us for further details: permissions@emeraldinsight.com 